\title{
Cognitive Decline in Patients with Anorexia Nervosa: Which Cognitive Domains are Most Vulnerable and Need to be Considered?
}

\author{
Adamski Natalia ${ }^{1}$, Rost Barbara ${ }^{2}$, Di Gallo Alain², Schmeck Klaus ${ }^{2}$, Opwis Klaus ${ }^{1}$, Weber Peter ${ }^{3}$ and Penner Iris-Katharina ${ }^{4,5 *}$ \\ ${ }^{1}$ Department of Cognitive Psychology and Methodology, University of Basel, Switzerland \\ ${ }^{2}$ Child and Adolescent Psychiatric Hospital, Psychiatric University Hospitals Basel, Switzerland \\ ${ }^{3}$ Division of Pediatric Neurology and Developmental Medicine, University Children's Hospital, Basel, Switzerland \\ ${ }^{4}$ COGITO Center for Applied Neurocognition and Neuropsychological Research, Düsseldorf, Germany \\ ${ }^{5}$ Department of Neurology, Medical Faculty, Heinrich-Heine University, Düsseldorf, Germany
}

\begin{abstract}
Objective: Besides physical complaints, patients with anorexia nervosa (AN) often suffer from cognitive problems. However, it is still a matter of debate whether a specific profile of cognitive disturbances underlies the disease, and if so, whether this profile contributes to the maintenance of the illness and also leads to the development of different subtypes of AN. The aim of the present study was to provide a more detailed knowledge on neuropsychological profiles in patients with AN using an extension of the Ravello Profile test-battery by working memory (WM) tests.

Method: Twenty-nine AN patients and 20 healthy controls $(\mathrm{HC})$ participated in the study. Neuropsychological performance was assessed by the Ravello Profile and WM tasks such as Digit Span and Corsi Blocks, 2- and 3-Back tasks, Symbol Digit Modalities Test, Paced Auditory Serial and Addition Task, as well as the Verbal Learning and Memory Test.

Results: AN patients showed subtle cognitive problems on certain measures including WM performance Compared to $\mathrm{HC}$, the AN group showed significantly worse performance in verbal short-term and long-term memory, visuospatial WM, inhibition, and switching abilities, subserving successful self-regulation.

Discussion: Our results speak in favour of relevance for WM decline in the context of AN. Therefore, tasks assessing visuospatial WM and information processing speed (IPS) should be added to existing test batteries such as the Ravello Profile.
\end{abstract}

Keywords: Anorexia nervosa; Cognition; Executive functions; Visual information processing; Working memory; Ravello profile

Abbreviation: AN-BP: Anorexia Nervosa Binge-Eating/Purging Type; AN-R: Anorexia Nervosa Restrictive Type; HC: Healthy Controls

\section{Introduction}

Anorexia nervosa (AN) is a serious disorder that is characterized not only by psychological, social and somatic factors (according to ICD-10 and DSM-IV-TR) but also by metabolic changes within the central nervous system $[1,2]$, by structural alterations in brain volume and cortical thickness [3], and functional alterations targeting network connectivity [4]. The latter changes seem to be associated with core symptoms of AN and impaired performance in executive functions (EF) comprising flexibility, inhibition, visuospatial processing and working memory (WM) [4-10]. It can be assumed that dysfunction in WM performance is related to preoccupying thoughts about food that may promote a more habitual and less flexible eating behavior [11] and serve as feasible factor for mental and behavioural symptoms in AN [6]. The concept of WM was developed by Baddeley and Hitch [12] and proposes an operational system to store, manipulate and update incoming goal-relevant information in light of distracting information and to cope flexibly with common challenges in everyday life. Their WM model encompasses three components such as the phonological loop, the visuospatial sketchpad and the central executive as an attentional control entity [13]. The central executive is responsible for executive subprocesses such as shifting flexibly between rehearsal strategies, switching attention on relevant information and inhibiting irrelevant information, updating of goal-relevant information, downregulation of unwanted affect, suppression of ruminative thoughts that on their part subserve EFs and mental flexibility [14]. Results regarding
WM deficits in AN have been inconsistent. There is evidence that verbal WM seems to be unaffected [15] whereas the central executive and the visuospatial aspect seem to be inefficient [16]. Furthermore various psychiatric disorders including obsessive-compulsive disorder (OCD) have also been linked to deficits in WM. OCD, a frequent comorbidity in AN [17] may also play a crucial role in the use of cognitive strategies to restraint appetite [18]. The aim of the present study was to evaluate whether WM tests will be of additional benefit when assessing subtle cognitive problems in patients with AN.

\section{Methods}

\section{Participants}

29 female participants were collected from the University Children's Hospital Basel (UKBB), Children and Adolescent Psychiatric Hospital Basel (KJPK), and the Psychiatric University Hospitals Basel and Psychiatric Hospitals Basel-Land (UPK BS, KPD BL), Clinic Sonnenhalde in Riehen, Children and Adolescent Psychiatric Hospital

*Corresponding author: Penner IK, Department of Neurology, Medical Faculty Heinrich-Heine University, Düsseldorf, Germany, Tel: + 49-211-220 588 12; E-mail: ik.penner@cogito-center.com

Received: August 18, 2017; Accepted: August 24, 2017; Published: August 31 2017

Citation: Natalia A, Barbara R, Alain DG, Klaus S, Klaus O, et al. (2017) Cognitive Decline in Patients with Anorexia Nervosa: Which Cognitive Domains are Most Vulnerable and Need to be Considered? Clin Exp Psychol 3: 162. doi: $10.4172 / 2471-2701.1000162$

Copyright: @ 2017 Natalia A, et al. This is an open-access article distributed under the terms of the Creative Commons Attribution License, which permits unrestricted use, distribution, and reproduction in any medium, provided the original author and source are credited. 
Lörrach (KJP), as well as from private practitioners. All participants met AN criteria according to ICD-10 (2nd edn.) and DSM-IV-TR (4th edn.) and had their disease onset between the ages of 10 and 18 years. At the time of assessment, 23 out of 29 patients suffered from anorexia nervosa restrictive subtype (AN-R) and 6 from anorexia nervosa bingeeating/purging subtype (AN-BP). Ages ranged from 11.5 years to 36.6 years (median $=20.0$ years, SD 6.6). 20 healthy control participants with no personal or family history of eating disorders, obsessive-compulsive disorder or other psychiatric or neuropsychological disorders were recruited from the faculty of psychology (Bachelor in Psychology) and by advertisement in clinical units. The ethics committee of the University of Basel approved the study and all participants gave informed written consent. In the case of participants being 16 years or younger, parental consent was additionally obtained.

\section{Materials}

\section{Psychometric measures}

Eating disorder symptoms were measured using the German version of the Eating Disorder Examination Questionnaire. To additionally assess other frequently occurring psychiatric disorders like depression, anxiety and obsessive-compulsive symptoms, stateof-the-art questionnaires for children, adolescents and adults were administered (Table 1).

\section{Neuropsychological tests}

All AN patients were investigated using the standardized assessment battery Ravello Profile which comprises the Rey-Osterrieth Complex Figure Test, the Brixton Spatial Anticipation task and several subtests from the Delis-Kaplan Executive Function System (Table 1). Further information and more detailed description may be reviewed elsewhere $[19,20]$. To control for verbal and performance intelligence the Vocabulary and Matrix Reasoning Task from the Wechsler Intelligence Scale were applied. In addition assessments to cover short-term, longterm and WM (WM) functions, as well as mental speed were applied including visuospatial and verbal tasks (Table 1). All tests were applied in a pre-defined order.

\section{Procedure}

All participants were interviewed at the beginning of the examination to collect demographic data. Afterwards, all participants underwent neuropsychological testing in the same default order (Table 1). First, participants completed the self-report measures followed by memory and WM tasks. Finally, all participants performed the Ravello Profile test-battery in a pre-defined order as recommended by Rose et al. [20]. The assessment in total lasted 2.5 to 3 hours and interruptions for about 15 minutes were allowed to guarantee that patients met their prescribed eating plans (Table 1).

\section{Statistical analyses}

All data were checked for normal distribution by the KolmogorovSmirnov test and the Levene's test for equality of variance. Since data were not normally distributed non-parametric tests comprising the Mann-Whitney $U$ test for group comparison between AN and HCs were applied ( $p$ value of 0.05 or less). All analyses were conducted using the IBM statistical package SPSS 20.0.

$\mathrm{Z}$-values corrected for age were calculated using normative data from the corresponding test manuals $[(\mathrm{x}-) / \mathrm{SD}]$. Therefore raw scores for the WM measures and scaled scores for the Ravello Profile tasks were used to compute age corrected $\mathrm{z}$-scores.

\begin{tabular}{|c|c|c|c|}
\hline & Instruments & Reference & Domains \\
\hline 1 & $\begin{array}{l}\text { Eating Disorder Examination } \\
\text { Questionnaire (EDE-Q) }\end{array}$ & $\begin{array}{c}\text { Hilbert and Tuschen-Caffier } \\
{[24]}\end{array}$ & \multirow{4}{*}{ Questionnaires } \\
\hline 2 & $\begin{array}{l}\text { Beck Depression Inventory- } \\
\text { II (BDI-II) / Depression } \\
\text { Inventory for Children and } \\
\text { Adolescents (DIKJ) }\end{array}$ & $\begin{array}{c}\text { Hautzinger et al. [25], } \\
\text { Stiensmeier-Pelster et al. } \\
{[26]}\end{array}$ & \\
\hline 3 & $\begin{array}{c}\text { Yale-Brown Obsessive } \\
\text { Compulsive Scale (Y-BOCS) } \\
\text { / Children Obsessive- } \\
\text { Compulsion Inventory } \\
\text { (ChoCl) }\end{array}$ & $\begin{array}{l}\text { short form; Büttner- } \\
\text { Westphal and Hand [27]; } \\
\text { translated Version from } \\
\text { Shafran et al. [28] }\end{array}$ & \\
\hline 4 & $\begin{array}{c}\text { State-Trait Anxiety Inventory } \\
\text { (STAI) / State-Trait Anxiety } \\
\text { Inventory for Children } \\
\text { (STAIK) }\end{array}$ & $\begin{array}{l}\text { Laux et al. [29], } \\
\text { Stiensmeier-Pelster [30] }\end{array}$ & \\
\hline 5 & $\begin{array}{l}\text { Symbol Digit Modality Test } \\
\text { (SDMT) }\end{array}$ & Smith [31] & \multirow{6}{*}{$\begin{array}{l}\text { Processing } \\
\text { speed and } \\
\text { Working memory }\end{array}$} \\
\hline 6 & $\begin{array}{c}\text { Verbaler Lern- und } \\
\text { Merkfähigkeitstest (VLMT) }\end{array}$ & Helmstaedter et al. [32] & \\
\hline 7 & $\begin{array}{l}\text { Corsi Blocks forward and } \\
\text { backward (WMS-R) }\end{array}$ & \multirow{2}{*}{$\begin{array}{c}\text { Wechsler Memory Scale - } \\
\text { Revised } \\
\text { Härting et al. [26] }\end{array}$} & \\
\hline 8 & $\begin{array}{l}\text { Digit Span forward and } \\
\text { backward (WMS-R) }\end{array}$ & & \\
\hline 9 & $\begin{array}{c}\text { 2-back and 3-back reaction } \\
\text { time and accuracy (TAP) } \\
\text { adaptation }\end{array}$ & $\begin{array}{c}\text { Test for Attentional } \\
\text { Performance } \\
\text { Zimmermann and Finn [33] }\end{array}$ & \\
\hline 10 & $\begin{array}{l}\text { Rey-Osterrieth Complex } \\
\text { Figure Copy Condition and } \\
\text { Immediate Recall (ROCF) }\end{array}$ & Osterrieth [34]; Rey [35] & \\
\hline 11 & $\begin{array}{c}\text { Verbal Fluency letter fluency, } \\
\text { category fluency and } \\
\text { category switching (D-KEFS) }\end{array}$ & $\begin{array}{l}\text { Delis-Kaplan Executive } \\
\text { Functions Test } \\
\text { Delis et al. [36] }\end{array}$ & \multirow{8}{*}{$\begin{array}{l}\text { Ravello Profile } \\
\text { testing executive } \\
\text { functions }\end{array}$} \\
\hline 12 & $\begin{array}{c}\text { Vocabulary Test (WAIS / } \\
\text { WISC) }\end{array}$ & $\begin{array}{l}\text { Wechsler Intelligence } \\
\text { Scale; von et al. [22] }\end{array}$ & \\
\hline 13 & $\begin{array}{c}\text { Rey-Osterrieth Complex } \\
\text { Figure Delayed Recall } \\
\text { (ROCF) }\end{array}$ & See above & \\
\hline 14 & $\begin{array}{c}\text { Matrix Reasoning Test (WAIS } \\
\text { / WISC) }\end{array}$ & See above & \\
\hline 15 & $\begin{array}{c}\text { Colour-Word Interference } \\
\text { Test (D-KEFS) }\end{array}$ & \multirow{2}{*}{ See above } & \\
\hline 16 & $\begin{array}{c}\text { Trail Making Test Condition } 4 \\
\text { (D-KEFS) }\end{array}$ & & \\
\hline 17 & $\begin{array}{c}\text { Brixton Spatial Anticipation } \\
\text { Test }\end{array}$ & Burgess and Shallice [37] & \\
\hline 18 & Tower of London (D-KEFS) & See above & \\
\hline
\end{tabular}

Table 1: Order of administered tests during neuropsychological examination.

Only for the Symbol Digit Modalities Test, 2-Back and 3-Back task, Brixton Spatial Anticipation test and the Central Coherence Index was computed according to Booth [21], mean and standard deviations from our $20 \mathrm{HCs}$ were used as normative sample instead. Z-scores for cognitive profiles of the AN and HCs group are illustrated in Figure 1.

\section{Results}

\section{Patients descriptive}

As shown in Table 2 there were no significant differences in age or intellectual level between the two groups. The healthy control group differed significantly from the AN group on BMI, eating psychopathology, depression, obsessive-compulsive symptoms and anxiety $(\mathrm{p}<0.001)$ (Table 2).

\section{Comparison between patients suffering from $\mathrm{AN}$ and $\mathrm{HCs}$ on neuropsychological performance}

To reveal significant discrepancies between patients with AN and 


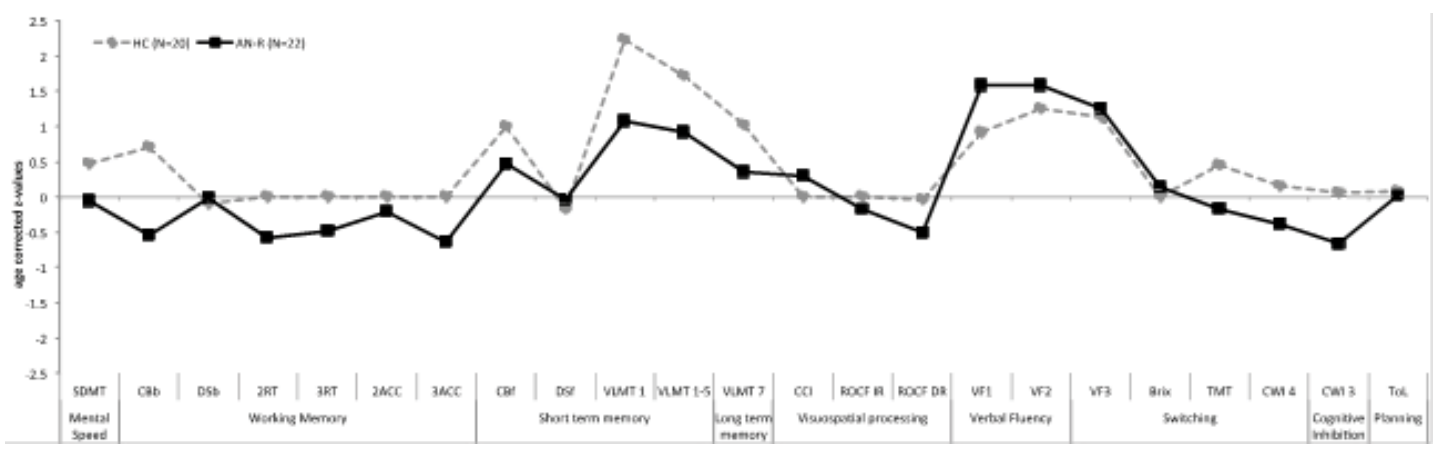

Note: AN-R: Anorexia nervosa restrictive type; HC: Healthy controls; SDMT: Symbol digit modality test; CBb: Corsi blocks backward; DSb: Digit span backward; 2RT/3RT: 2 Back/3 Back reaction time; 2ACC/3ACC: 2 Back/3 Back accuracy; CBf: Corsi blocks forward; DSf: Digit span forward; VLMT: Verbaler Lern- und Merkfähigkeitstest; $\mathrm{CCl}$ : Central coherence index; ROCF IR: Rey-Osterrieth complex figure test immediate recall; ROCF DR: Rey-Osterrieth complex figure test delayed recall; VF: Verbal fluency task; Brix: Brixton spatial anticipation test; TMT: Trail making test; CWI: Colour-word interference test; ToL: Tower of london

Figure 1: Mean z-scores calculated for each neuropsychological test.

\begin{tabular}{|c|c|c|c|c|}
\hline & & \multicolumn{2}{|c|}{ Median } & \multirow{2}{*}{$\begin{array}{l}\text { Kolmogorov- } \\
\text { Smirnov Test }\end{array}$} \\
\hline & & $\begin{array}{l}\text { Anorexia nervosa } \\
\qquad(\mathrm{N}=29)\end{array}$ & $\begin{array}{l}\text { Healthy controls } \\
\qquad(\mathrm{N}=20)\end{array}$ & \\
\hline & Age & 20.0 & 20.1 & n.s. \\
\hline & In/Outpatients & $14 / 15$ & - & - \\
\hline & Duration of illness (months) & 48.0 & - & - \\
\hline & Verbal IQ Vocabulary & 48.0 & 51.0 & n.s. \\
\hline & Performance IQ Matrices & 22.0 & 21.0 & n.s. \\
\hline & Body mass index $\left(\mathrm{kg} / \mathrm{m}^{2}\right)$ & 16.0 & 21.3 & $<0.001$ \\
\hline & Lowest weight (kg) & 37.0 & - & - \\
\hline \multicolumn{5}{|c|}{ Eating disorder psychopathology } \\
\hline Eating & order Examination Questionnaire ${ }_{\text {global raw score }}$ & 11.2 & 1.6 & $<0.001$ \\
\hline \multicolumn{5}{|c|}{ Depression } \\
\hline Beck Depress & $\begin{array}{l}\text { Inventory II / Depression Inventory for Children and } \\
\text { Adolescents }\end{array}$ & 24.0 & 4.5 & $<0.001$ \\
\hline \multicolumn{5}{|c|}{ Anxiety } \\
\hline State & $\begin{array}{c}\text { State-Trait Anxiety Inventory / State-Trait Anxiety } \\
\text { Inventory for Children }\end{array}$ & 42.0 & 31.0 & 0.009 \\
\hline Trait & $\begin{array}{l}\text { State-Trait Anxiety Inventory / State-Trait Anxiety } \\
\text { Inventory for Children }\end{array}$ & 50.0 & 36.0 & 0.002 \\
\hline \multicolumn{5}{|c|}{ Obsessions-Compulsions } \\
\hline Obsessions & $\begin{array}{c}\text { Yale-Brown Obsessive Compulsive Scale / Children } \\
\text { Obsessive-Compulsion Inventory }\end{array}$ & 10.0 & 0.0 & $<0.001$ \\
\hline Compulsions & $\begin{array}{c}\text { Yale-Brown Obsessive Compulsive Scale / Children } \\
\text { Obsessive-Compulsion Inventory }\end{array}$ & 8.0 & 0.0 & 0.001 \\
\hline
\end{tabular}

Table 2: Demographic and clinical data.

HCs a Mann-Whitney U test was applied. The AN group showed significantly lower scores on domains of verbal short-term and longterm memory, visuospatial WM, visuospatial long-term memory, inhibition, and switching as can be seen in Table 3. In contrast, the AN patients reached superior results than controls for phonemic fluency (Table 3).

\section{Comparison between the AN-R subtype and HCs on neuropsychological performance}

Since there is evidence that restrictive AN patients show specific cognitive problems on cognitive flexibility $[9,22]$ in comparison to binge-eating/purging AN subtype exploratory analyses were conducted using the AN-R subtype only. Table 4 illustrates the results for the comparison between the AN-R subtype and the $\mathrm{HC}$ group as revealed by the Mann-Whitney $U$ test $(p<0.05)$. Significant differences were found for verbal short-term and long-term memory, visuospatial WM, inhibition, and for tasks measuring switching abilities. Additionally two measures for information processing speed (IPS) also became significant when comparing the AN-R group to the HCs. In contrast, the aforementioned significant lower score on visuospatial long-term memory measured by the Rey-Osterrieth Figure Test Delayed Recall and the significant higher score on phonemic fluency did not remain significant in the subgroup analysis.

\section{Mean z-scores corrected for age displayed in a profile}

Figure 1 exhibits the mean age corrected $\mathrm{z}$-scores for the AN-R subtype group and HCs showing cognitive performance between both groups on all measures (Table 4).

\section{Discussion}

The aim of the present study was to evaluate whether it might be of benefit to add WM tests to the Ravello Profile in detecting subtle cognitive problems. 
Citation: Natalia A, Barbara R, Alain DG, Klaus S, Klaus O, et al. (2017) Cognitive Decline in Patients with Anorexia Nervosa: Which Cognitive Domains are Most Vulnerable and Need to be Considered? Clin Exp Psychol 3: 162. doi: 10.4172/2471-2701.1000162

Page 4 of 6

\begin{tabular}{|c|c|c|c|c|c|c|}
\hline & & & Anorexia nervosa & $\begin{array}{l}\text { Healthy } \\
\text { controls }\end{array}$ & $\begin{array}{c}\text { Mann-Whitney } \\
\text { U Test }\end{array}$ & $\begin{array}{c}\text { Effect } \\
\text { size }\end{array}$ \\
\hline \multicolumn{3}{|c|}{ Working memory } & Median & Median & 2-tailed $p=.05$ & d-Mdn \\
\hline Information processing speed & \multicolumn{2}{|c|}{ Symbol Digit Modality Test } & 63.0 & 68.5 & 0.083 & -0.50 \\
\hline \multirow{3}{*}{ Verbal short-term memory } & \multirow{3}{*}{$\begin{array}{l}\text { Verbaler Lern- and } \\
\text { Merkfähigkeitstest }\end{array}$} & Trail 1 & 9.0 & 12.0 & $<0.001^{*}$ & -1.47 \\
\hline & & Trail 1-5 & 61.0 & 69.0 & $0.001^{*}$ & -1.52 \\
\hline & & Trail 7 & 13.0 & 15.0 & $0.017^{*}$ & -0.95 \\
\hline \multirow{2}{*}{$\begin{array}{l}\text { Visuospatial short-term and } \\
\text { working memory }\end{array}$} & \multirow{2}{*}{ Corsi Blocks } & forward & 10.0 & 10.0 & 0.095 & -0.81 \\
\hline & & backward & 9.0 & 10.0 & $0.009^{*}$ & -0.57 \\
\hline \multirow{2}{*}{$\begin{array}{l}\text { Verbal short-term and } \\
\text { working memory }\end{array}$} & \multirow{2}{*}{ Digit Span } & forward & 8.0 & 7.0 & 0.675 & 0.38 \\
\hline & & backward & 7.0 & 6.5 & 0.387 & 0.39 \\
\hline \multirow{4}{*}{$\begin{array}{l}\text { Information processing speed and working } \\
\text { memory }\end{array}$} & \multirow{2}{*}{ 2-back } & Reaction time & 766.5 & 614.2 & 0.098 & -0.59 \\
\hline & & Accuracy & 55.0 & 56.5 & 0.229 & -0.32 \\
\hline & \multirow{2}{*}{ 3-back } & Reaction time & 866.4 & 810.3 & 0.231 & -0.20 \\
\hline & & Accuracy & 48.0 & 50.0 & 0.158 & -0.36 \\
\hline \multicolumn{7}{|l|}{ Ravello Profile } \\
\hline Central Coherence & \multirow{3}{*}{$\begin{array}{c}\text { Rey-Osterrieth Complex Figure } \\
\text { Test }\end{array}$} & Copy & 1.3 & 1.3 & 0.339 & 0.02 \\
\hline \multirow{2}{*}{$\begin{array}{l}\text { Visuospatial short-term and } \\
\text { long-term memory }\end{array}$} & & Immediate recall & 22.0 & 22.3 & 0.659 & -0.05 \\
\hline & & Delayed Recall & 21.0 & 23.5 & $0.037^{*}$ & -0.75 \\
\hline \multirow{2}{*}{ Fluency } & \multirow{3}{*}{ Verbal Fluency ${ }^{\alpha}$} & 1.Letter fluency & 15.0 & 12.0 & $0.014^{*}$ & 0.96 \\
\hline & & 2.Category fluency & 15.0 & 14.0 & 0.357 & 0.30 \\
\hline Switching & & 3.Category switch & 14.0 & 13.5 & 0.750 & 0.16 \\
\hline Inhibition & \multirow[b]{2}{*}{ Colour-Word Interference Test ${ }^{\alpha}$} & 3.Naming colour & 9.0 & 10.0 & $0.036^{*}$ & -0.40 \\
\hline \multirow[t]{2}{*}{ Switching } & & $\begin{array}{l}\text { 4. Naming colour }+ \\
\text { Reading }\end{array}$ & 9.0 & 10.5 & $0.050^{*}$ & -0.60 \\
\hline & Trail Making Test ${ }^{\alpha}$ & Condition 4 & 10.0 & 11.0 & $0.043^{*}$ & -0.43 \\
\hline Flexibility & \multicolumn{2}{|c|}{ Brixton Spatial Anticipation Test ${ }^{\alpha}$} & 7.0 & 7.0 & 0.962 & 0.00 \\
\hline Planning & Tower of London ${ }^{\alpha}$ & Total achievement & 10.0 & 10.0 & 0.658 & 0.00 \\
\hline
\end{tabular}

Note: $\alpha$ : Scaled scores

Table 3: Neuropsychological performances in healthy controls and anorexia nervosa patients.

\begin{tabular}{|c|c|c|c|c|c|c|c|}
\hline & & & restrictive type & controls & Smirnov & U Test & size \\
\hline \multicolumn{3}{|c|}{ Working memory } & Median & Median & 2-tailed $p=.05$ & 2-tailed $p=.05$ & d \\
\hline Information processing speed & \multicolumn{2}{|c|}{ Symbol Digit Modality Test } & 61.0 & 68.5 & $0.044^{*}$ & $0.016^{*}$ & -0.72 \\
\hline \multirow{3}{*}{ Verbal short-term memory } & \multirow{3}{*}{$\begin{array}{l}\text { Verbaler Lern- and } \\
\text { Merkfähigkeitstest }\end{array}$} & Trail 1 & 9.0 & 12.0 & $<0.001^{*}$ & $<0.001^{*}$ & -1.40 \\
\hline & & Trail 1-5 & 61.0 & 69.0 & $0.006^{*}$ & $0.001^{*}$ & -1.68 \\
\hline & & Trail 7 & 12.0 & 15.0 & $0.012^{*}$ & $0.008^{*}$ & -1.29 \\
\hline \multirow{2}{*}{$\begin{array}{l}\text { Visuospatial short-term and } \\
\text { working memory }\end{array}$} & \multirow{2}{*}{ Corsi Blocks } & forward & 9.0 & 10.0 & 0.113 & 0.069 & -0.85 \\
\hline & & backward & 8.0 & 10.0 & $0.005^{*}$ & $0.001^{*}$ & -0.68 \\
\hline \multirow{2}{*}{$\begin{array}{l}\text { Verbal short-term and } \\
\text { working memory }\end{array}$} & \multirow{2}{*}{ Digit Span } & forward & 7.0 & 7.0 & 0.797 & 0.694 & 0.13 \\
\hline & & backward & 7.0 & 6.5 & 0.917 & 0.795 & 0.40 \\
\hline \multirow{4}{*}{$\begin{array}{l}\text { Information processing speed } \\
\text { and working memory }\end{array}$} & \multirow{2}{*}{ 2-back } & Reaction time & 852.6 & 614.2 & 0.068 & $0.048^{*}$ & -0.92 \\
\hline & & Accuracy & 53.5 & 56.5 & 0.214 & 0.149 & -0.61 \\
\hline & \multirow{2}{*}{ 3-back } & Reaction time & 920.0 & 810.3 & 0.173 & 0.098 & -0.40 \\
\hline & & Accuracy & 48.0 & 50.0 & 0.100 & 0.118 & -0.35 \\
\hline \multicolumn{8}{|c|}{ Ravello Profile } \\
\hline Central Coherence & \multirow{3}{*}{$\begin{array}{c}\text { Rey-Osterrieth Complex } \\
\text { Figure Test }\end{array}$} & Copy & 1.3 & 1.3 & 0.262 & 0.387 & 0.02 \\
\hline \multirow{2}{*}{$\begin{array}{l}\text { Visuospatial short-term and } \\
\text { long-term memory }\end{array}$} & & Immediate recall & 21.8 & 22.3 & 0.583 & 0.622 & -0.09 \\
\hline & & Delayed Recall & 21.0 & 23.5 & 0.144 & 0.077 & -0.56 \\
\hline \multirow{2}{*}{ Fluency } & \multirow{3}{*}{ Verbal Fluency ${ }^{\alpha}$} & 1.Letter fluency & 14.0 & 12.0 & 0.091 & 0.065 & 0.63 \\
\hline & & 2.Category fluency & 14.0 & 14.0 & 0.507 & 0.425 & 0.00 \\
\hline Switching & & 3.Category switch & 14.0 & 13.5 & 0.966 & 0.966 & 0.16 \\
\hline Inhibition & \multirow{2}{*}{$\begin{array}{c}\text { Colour-Word } \\
\text { Interference Test }{ }^{\alpha}\end{array}$} & 3.Naming colour & 8.0 & 10.0 & $0.031^{*}$ & $0.009^{*}$ & -0.80 \\
\hline \multirow[t]{2}{*}{ Switching } & & $\begin{array}{l}\text { 4. Naming colour + } \\
\text { Reading }\end{array}$ & 8.0 & 10.5 & $0.029^{*}$ & $0.038^{*}$ & -0.96 \\
\hline & Trail Making Test ${ }^{\alpha}$ & Condition 4 & 10.0 & 11.0 & 0.127 & $0.033^{*}$ & -0.42 \\
\hline Flexibility & \multicolumn{2}{|c|}{ Brixton Spatial Anticipation Test ${ }^{\alpha}$} & 8.0 & 7.0 & 0.879 & 0.817 & 0.70 \\
\hline Planning & Tower of London ${ }^{\alpha}$ & Total achievement & 11.0 & 10.0 & 0.987 & 0.927 & 0.40 \\
\hline
\end{tabular}

Note: $\alpha$ : Scaled scores

Table 4: Neuropsychological measures for anorexia nervosa restrictive subtype and healthy controls. 
Using age corrected $\mathrm{z}$-scores significant lower scores were found on visuospatial memory, inhibition and switching measured with tests from the Ravello Profile test-battery in the AN group. In addition highly significant lower scores were detected on verbal short-term, long-term memory and visuospatial WM assessed with the additional WM tests. These findings are in line with current literature $[10,19]$ and reflect three basic domains including shifting, inhibition and updating that are related to EFs and play a crucial and subserving role in selfregulating processes [14].

The current study included patients suffering from both AN subtypes. Current literature suggests contraries in test results considering AN subtypes. Individuals suffering from AN-R subtype may show worse performance on response inhibition, cognitive flexibility and visuospatial processing than individuals suffering from AN-BP $[9,22]$.

With a focus on WM there is still a lack of congruence within neuropsychological performance. WM refers to the ability to actively maintain, manipulate and store information, which is necessary to shield goal-relevant information from distraction [14]. Some studies show no differences between $\mathrm{HC}$ and $\mathrm{AN}$ in processing verbal WM tasks at the beginning of AN but a trend towards lower performance with increasing duration of illness [15]. Other studies show that individuals who restrict food intake in comparison to binge eating and purging seem to be associated with superior WM performance but were compromised only when subliminal images of food were presented [6]. In other studies, by contrast, individuals suffering from AN performed worse on visuospatial WM tasks [10]. To take this incongruence into account our study aimed to follow-up and to minimize heterogeneity of the current sample by using additional exploratory analyses in patients suffering from AN-R subtype only. Interestingly the AN-R group showed not only highly significant decline in domains of verbal shortterm, long-term memory and visuospatial WM but also in inhibition and switching when compared to HC.

There seems to be a dynamic relationship between WM, inhibition and switching regarding self-regulatory processes. All three broad facets base on directing executive attention to goal-relevant information and shielding this information against distraction [14]. This executive control is a component of the multi-store model by Baddeley and Hitch [12], which coordinates the limited attention to process incoming goal-directed information [13]. The information processing speed (IPS) is necessary to deal with different amounts of information and is a measure of the efficiency of mental function. Our results are in line with previous studies assessing inefficient IPS and visuospatial WM in patients suffering from AN [8,10]. The study by Oltra-Cucarella et al. [8] found that the interaction of IPS and EF played a major role. This kind of pattern of making trade-offs between speed and accuracy was also detectable in the current study: with the help of other assessment tools standard results were achieved in time-based components measuring inhibition and switching, and elevated scores on IPS and WM. All used tests required skills in visual converting of the test material including attention and visuospatial information processing and may reflect cognitive problems in the central executive and the visual sketchpad [16]. Therefore, to detect subtle cognitive change in patients suffering from AN-R and to account for inefficiencies in higher cognitive performance style WM tasks should be added to refine AN sensitive batteries such as the Ravello Profile used to characterize AN [5].

Looking at central coherence in particular, the AN-R group did not show differences in performance in comparison to HCs which is in line with results by Rose et al. [23] and Stedal et al. [19] but in contrast to results from van Autreve et al. (2013). The latter group reported a decreased performance for the AN-R group compared to the AN-BP and HC group using different tests (Block Design (BD) and Object Assembly (OA)). Rose et al. [23] argue for more appropriate normative data in consideration of developmental trajectories in the general population. Further comparative studies using equal measures are needed to investigate central coherence abilities in HCs and patients suffering from different AN subtypes.

With a focus on verbal fluency also measuring mental flexibility by free association of words under a time-constrained condition all AN participants performed in above average range [19]. In line with previous studies our results show that the AN-R participants revealed differences in verbal short-term and long-term memory as well as verbal learning when compared to HCs. The study by Weider et al. [10] showed inferior verbal performance of patients suffering from AN using a different test (California Verbal Learning Test-II) that required serial wordlist learning being similar to the test that was used in our study regarding verbal learning and memory. The participants performed worse than the HCs even after adjusting for nadir of body mass index and depression symptoms [10]. Oltra-Cucarella et al. [8] found that IPS and inhibition account for almost $80 \%$ of the variance on verbal memory in patients suffering from AN. The authors suggested that impaired basic cognitive abilities such as IPS might influence other cognitive functions such as verbal or visuospatial memory and might be included as covariates to control for other cognitive abilities. Future research approaches should take this remark into consideration.

\section{Limitations}

This study has some limitations, which have to be considered. First, since the sample size for the AN group was small, results and conclusions have to be taken with caution and might rather act as hints for further research intentions. Second, the study sample is characterized by a heterogeneity in terms of age, duration of illness, comorbidities, therapeutically settings and age of onset that could not be statistically controlled due to sample size reasons. All these variables might affect the results by concealing possible cognitive problems and should be controlled for in further research efforts. Nevertheless the results hint at subtle changes of cognitive performance not only in the domains of visuospatial processing, inhibition and switching but especially in the context of WM. Third, results for AN-R revealed subtle cognitive problems in several cognitive aspects including inhibition, switching and visuospatial WM which are basic facets of EFing and might subserve self-regulation. It was not possible to compare both AN subtypes on neuropsychological tests performance because of the small sample size of the AN-BP group.

\section{Conclusion}

The application of a neuropsychological test-battery including both tests of EFs and tests assessing IPS and visuospatial WM appears to be suitable to detect specific but subtle cognitive problems in patients suffering from AN-R subtype. Our findings are in line with current research approaches and suggest adhering to the idea to focus on visuospatial WM and IPS in patients with AN.

\section{Acknowledgments}

The authors thank all colleagues in the local Eating Disorder units of Base City, Basel Land, Riehen and Lörrach (Germany) for their support in recruiting participants for our research.

\section{References}

1. Mainz V, Schulte-Rüther M, Fink GR, Herpertz-Dahlmann B, Konrad K (2012) 
Citation: Natalia A, Barbara R, Alain DG, Klaus S, Klaus O, et al. (2017) Cognitive Decline in Patients with Anorexia Nervosa: Which Cognitive Domains are Most Vulnerable and Need to be Considered? Clin Exp Psychol 3: 162. doi: 10.4172/2471-2701.1000162

Structural brain abnormalities in adolescent anorexia nervosa before and after weight recovery and associated hormonal changes. Psychosoma Med 74:574582.

2. Roser W, Bubl R, Buergin D, Seelig J, Radue EW, et al. (1999) Metabolic changes in the brain of patients with anorexia and bulimia nervosa as detected by proton magnetic resonance spectroscopy. Int J Eat Disord 26: 119-136.

3. King JA, Geisler D, Ritschel F, Boehm I, Seidel M, et al. (2015) Global cortical thinning in acute anorexia nervosa normalizes following long-term weight restoration. Biol Psychiatry 77: 624-632.

4. Gaudio S, Piervincenzi C, Zobel BB, Montecchi FR, Riva G, et al. (2015) Altered resting state functional connectivity of anterior cingulate cortex in drug naïve adolescents at the earliest stages of anorexia nervosa. Sci Rep 5: 10818.

5. Reville MC, O'Connor L, Frampton I (2016) Literature review of cognitive neuroscience and anorexia nervosa. Curr Psychiatry Rep 18: 1-8.

6. Brooks SJ (2016) A debate on working memory and cognitive control: Can we learn about the treatment of substance use disorders from the neural correlates of anorexia nervosa? BMC Psychiatry 16: 1.

7. Biezonski D, Cha J, Steinglass J, Posner J (2015) Evidence for thalamocortical circuit abnormalities and associated cognitive dysfunctions in underweight individuals with anorexia nervosa. Neuropsychopharmacology 41: 1560-8.

8. Oltra-Cucarella J, Rojo Moreno L, Arribas Sàiz P, Sanguesa García C, Latorre Paniagua $P$, et al. (2015) Impaired executive functioning influences verbal memory in anorexia nervosa. Eat Behav 16: 47-53.

9. Wu M, Brockmeyer T, Hartmann M, Skunde M, Herzog W, et al. (2014) Setshifting ability across the spectrum of eating disorders and in overweight and obesity: a systematic review and meta-analysis. Psychol Med 44: 3365-3385.

10. Weider S, Indredavik MS, Lydersen S, Hestad K (2015) Neuropsychological function in patients with anorexia nervosa or bulimia nervosa. Int $\mathrm{J}$ Eat Disord 48: $397-405$

11. Higgs S (201) Cognitive processing of food rewards.

12. Baddeley AD, Hitch G (1974) Working memory. Psychol Learn Motiv 8: 47-89.

13. Baddeley AD (2003) Working memory: Looking back and looking forward. Nat Rev Neurosci 4: 829 - 839 .

14. Hofmann W, Schmeichel BJ, Baddeley AD (2012) Executive functions and selfregulation. Trends Cogn Sci 16: 174-180.

15. Lao-Kaim NP, Giampietro VP, Williams SC, Simmons A, Tchanturia K (2014) Functional MRI investigation of verbal working memory in adults with anorexia nervosa. Eur Psychiatry 29: 211-218.

16. Kemps E, Tiggemann M, Wade T, Ben-Tovim D, Breyer R (2006) Selective working memory deficits in anorexia nervosa. Eur Eat Disord Rev 14: 97-103.

17. Hirani V, Serpell L, Willoughby K, Neiderman M, Lask B (2010) Typology of obsessive-compulsive symptoms in children and adolescents with anorexia nervosa. Eat Weight Disord 15: 86-89.

18. Brooks SJ, Dahlberg LS, Swenne I, Aronsson M, Zarei S, et al. (2014) Obsessive-compulsivity and working memory are associated with differential prefrontal cortex and insula activation in adolescents with a recent diagnosis of an eating disorder. Psychiatry Res 224: 246-253

19. Stedal K, Frampton IJ, Landro NI, Lask B (2012) The Neuropsychological profile of children, adolescents, and young adults with anorexia nervosa. Arch Clin Neuropsychol 27: 329-337.

20. Rose M, Davis J, Frampton IJ, Lask B (2011) The Ravello Profile: Developmen of a global standard neuropsychological assessment for young people with anorexia nervosa. Clin Child Psychol Psychiatry 16: 195-202.
21. Booth $R$ (2006) Local-global processing and cognitive style in autism spectrum disorders and typical development. University of London, London.

22. von Aster M, Neubauer A, Horn R (2006) Wechsler Intelligenztest für Erwachsene WIE. Deutschsprachige Bearbeitung und Adaptation des WAIS-III von David Wechsler.

23. Rose M, Frampton IJ, Lask B (2014) Central coherence, organizationa strategy, and visuospatial memory in children and adolescents with anorexia nervosa. Appl Neuropsychol Child 3: 284-296.

24. Hilbert A, Tuschen-Caffier B (2006) Eating disorder examination questionnaire (EDE-Q), Deutschsprachige Version.

25. Hautzinger M, Keller F, Kühner C (2006) Das Beck Depressionsinventar II. Deutsche Bearbeitung und Handbuch zum BDI II. Frankfurt am Main: Hartcourt Test Services.

26. Härting C, Markowitsch HJ, Neufld H, Calabrese P, Deisinger K (2000) WMS-R Wechsler Gedächtnis Test - Revidierte Fassung.

27. Büttner-Westphal H, Hand I (1991) Yale-brown obsessive compulsive scale (Y-BOCS). Verhaltenstherapie 1: 226-233.

28. Shafran R, Frampton IJ, Heyman I, Reynolds M, Teachman B, et al. (2003) The preliminary development of a new self-report measure for OCD in young people (translated Version; short-form). J Adolesc 26: 137-142.

29. Laux L, Glanzmann P, Schaffner P, Spielberger CD (1981) State-TraitAngstinventar (Testmappe mit Handanweisung, Fragebogen STAI-G Form X 1 und Fragebogen STAI-G Form X 2).

30. Stiensmeier-Pelster J, Braune-Krickau M, Schürmann M, Duda K (2000) Depressionsinventar für Kinder und Jugendliche (DIKJ).

31. Smith A (19763) Symbol digit modality test. Western Psychological Services, Los Angeles.

32. Helmstaedter C, Lendt M, Lux S (2001) Verbaler Lern- und Merkfähigkeitstest (VLMT). Hogrefe, Göttingen.

33. Zimmermann P, Fimm B (1992) Testbatterie zur Aufmerksamkeitsprüfung

34. Osterrieth $P(1944)$ Le teste de copie d'une figure complexe (The test of copying a complex figure). Arch Psychol 30: 206-356.

35. Rey A (1941) L'examen psychologique dans les cas d'encephalopathie traumatique (Psychological examination of traumatic encephalopathy). Arch Psychol 28: 286-340.

36. Delis D, Kaplan E, Kramer J (2001) Delis Kaplin executive function system. The Psychological Corporation, San Antonio.

37. Burgess P, Shallice T (1997) The Hayling and Brixton Tests Manual. Thames Valley Test Company, Bury St Edmunds. 